\title{
A Response to: Letter to the Editor Regarding "Agreement Between Trend-Based and Qualitative Analysis of the Retinal Nerve Fiber Layer Thickness for Glaucoma Progression on Spectral-Domain Optical Coherence Tomography"
}

\author{
Atalie C. Thompson · Sanjay Asrani
}

Received: November 3, 2021 / Accepted: November 23, 2021 / Published online: December 6, 2021

(C) The Author(s) 2021

We thank Hwang et al. for their thoughtful letter in response to our recently published article [1], and we agree with their astute observation that peripapillary retinal nerve fiber layer (RNFL) retinoschisis further contributed to a false appearance of progression in our case example presented in Fig. 2. Several prior studies have described the co-prevalence of peripapillary RNFL retinoschisis in eyes with glaucoma [2-5], which may impact approximately $6 \%$ of glaucoma patients according to two recent cohort studies $[3,4]$. In both of these studies, peripapillary RNFL retinoschisis was significantly more likely to be present in glaucomatous compared to healthy eyes [3, 4]. Van der Schoot et al. detected focal peripapillary RNFL retinoschisis in 7 of 117 glaucomatous eyes and 0 of 91 healthy control eyes [4]. Similarly, in the Investigating Glaucoma Progression Study, Lee and colleagues reported that peripapillary RNFL retinoschisis was present in 5.9\% of glaucoma cases compared to only $0.5 \%$ of healthy controls. Of note, in a multivariate model, higher intraocular pressure at the time of spectral domain-optical coherence

A. C. Thompson · S. Asrani $(\bowtie)$

Department of Ophthalmology, Duke University, Box 3802, Durham, NC 27710, USA

e-mail: sanjay.asrani@duke.edu

A. C. Thompson

Wake Forest Baptist Health, Winston Salem, NC, USA tomography (SD-OCT) scan was also significantly associated with the presence of peripapillary retinoschisis (odds ratio $=1.48$, $p=0.001)$.

Several groups have observed that peripapillary RNFL retinoschisis is often topographically correlated with an RNFL defect, and can thus impact correct interpretation of the true RNFL thickness [2-5], as it did in our case example. Thus, care should be taken not to overestimate the RNFL thickness whenever such retinoschisis is noted on review of the SD-OCT imaging. Moreover, such peripapillary retinoschisis is typically a transient phenomenon [2-5]. Fortunately, peripapillary RNFL retinoschisis only rarely extends into the macula [5], and tends to spontaneously resolve without any impact on visual function or evidence of glaucomatous progression [2-5]. Thus, when reviewing serial SD-OCT in patients with glaucoma, it is critical to neither overestimate the RNFL thickness in eyes with retinoschisis, nor erroneously attribute the resolution of such retinoschisis to glaucomatous progression.

\section{ACKNOWLEDGEMENTS}

Funding. No funding or sponsorship was received for the publication of this article. 
Authorship. All named authors meet the International Committee of Medical Journal Editors (ICMJE) criteria for authorship for this article, take responsibility for the integrity of the work as a whole, and have given their approval for this version to be published.

Author Contributions. All authors contributed to the study conception and design. Drafting of manuscript (ACT); revision and approval of final manuscript (ACT, SA).

Disclosures. Dr. Asrani receives lecture honoraria from Heidelberg Engineering, Franklin, MA and from Sophia Laboratories, Mexico City. He is a consultant to Alievio. Dr. Thompson receives grant support from the American Glaucoma Society and the NEI 7K23 EY030897.

Compliance with Ethics Guidelines. This article is based on previously conducted studies and does not contain any new studies with human participants or animals performed by any of the authors.

Data Availability. Data sharing is not applicable to this article as no datasets were generated or analyzed.

Open Access. This article is licensed under a Creative Commons Attribution-NonCommercial 4.0 International License, which permits any non-commercial use, sharing, adaptation, distribution and reproduction in any medium or format, as long as you give appropriate credit to the original author(s) and the source, provide a link to the Creative Commons licence, and indicate if changes were made. The images or other third party material in this article are included in the article's Creative Commons licence, unless indicated otherwise in a credit line to the material. If material is not included in the article's Creative Commons licence and your intended use is not permitted by statutory regulation or exceeds the permitted use, you will need to obtain permission directly from the copyright holder. To view a copy of this licence, visit http://creativecommons.org/licenses/by$\mathrm{nc} / 4.0 /$.

\section{REFERENCES}

1. Thompson AC, Li A, Asrani S. Agreement between trend-based and qualitative analysis of the retinal nerve fiber layer thickness for glaucoma progression on spectral-domain optical coherence tomography. Ophthalmol Ther. 2021;10(3):629-42.

2. Hwang $\mathrm{YH}$, et al. Effect of peripapillary retinoschisis on retinal nerve fibre layer thickness measurement in glaucomatous eyes. Br J Ophthalmol. 2014;98(5): 669-74.

3. Lee EJ, et al. Peripapillary retinoschisis in glaucomatous eyes. PLoS ONE. 2014;9(2):e90129.

4. van der Schoot J, Vermeer KA, Lemij HG. Transient peripapillary retinoschisis in glaucomatous eyes. J Ophthalmol. 2017;2017:1536030.

5. Dhingra $\mathrm{N}$, et al. Peripapillary schisis in open-angle glaucoma. Eye (Lond). 2017;31(3):499-502. 